\title{
A Canadian physician survey of dyspepsia management
}

Naoki Chiba MD FRCPC ${ }^{1,2}$, Lisa Bernard BA ${ }^{3}$, Bernie J O’Brien $\mathrm{PhD}^{4}$, Ron Goeree MA ${ }^{4}$, Richard H Hunt MD FRCP(Edin) FRCPC ${ }^{2}$

N Chiba, L Bernard, BJ O’Brien, R Goeree, RH Hunt. A Canadian physician survey of dyspepsia management. Can J Gastroenterol 1998;12(1):83-90.

OBJECTIVE: To determine the management of patients with new onset dyspepsia by Canadian family physicians.

METHODS: A survey was mailed to 195 family physicians in August 1995 to identify how they manage dyspepsia in patients according to four scenarios: based on presenting symptoms alone; assuming Helicobacter pylori-positive; known to be H pylori-negative; and endoscopically confirmed nonulcer dyspepsia.

RESULTS: A total of 170 of 195 physicians (87.2\%) completed the survey. Physicians reported that $7.3 \%$ of their practice is devoted to dyspepsia and $23 \%$ of these dyspeptic patients present for the first time. Ninety-three per cent of family physicians find a symptom classification of ulcer-, reflux- and dysmotility-like dyspepsia helpful. The majority of patients are advised to make lifestyle changes and are treated with antacids or empiric drug therapy. $\mathrm{A} \mathrm{H}_{2}$ receptor antagonist was the drug of choice for ulcer and reflux-like dyspepsia, while prokinetics were often used for reflux and dysmotility-like dyspepsia. After failure of initial treatment, patients were given another course of empiric treatment, commonly with cisapride or omeprazole. Family physicians estimated that the mean time to obtain a gastrointestinal consult was five weeks, and $70 \%$ indicated that this time to consult adversely influenced their decision to refer. If this time was reduced to less than two weeks, responding physicians would consider referring all eligible patients. On average, two to 2.5 courses of empiric therapy were given before referral. If $H$ pylori status was known, fewer empiric treatments (mean 1.8) were given before gastroenterological referral compared with the other scenarios. If the patient had nonulcer dyspepsia, $30 \%$ of family physicians provided reassurance only and did not prescribe empiric drug treatment.
CONCLUSIONS: Most newly dyspeptic patients in Canada are treated with empiric therapy according to symptom classification and referred for endoscopy after an average two to 2.5 treatment courses.

Key Words: Dyspepsia, Helicobacter pylori, Management, Primary care, Questionnaire, Survey

\section{Sondage sur le traitement de la dyspepsie auprès des médecins canadiens}

OBJECTIF : Déterminer de quelle façon les médecins de famille canadiens traitent leurs patients atteints de dyspepsie de fraîche date. MÉTHODES : Un sondage a été envoyé à 195 médecins de famille en août 1995 afin de les interroger sur la façon dont ils traitent la dyspepsie chez les patients selon quatre scénarios : selon les symptômes au moment de la présentation seule, en supposant la présence d'Helicobacter pylori, en supposant que le patient est $H$. pylori-négatif et en présence d'une dyspepsie non ulcéreuse confirmée à l'endoscopie.

RÉSULTATS : En tout, 170 médecins sur 195 (87,2 \%) ont répondu au sondage. Selon les résultats, 7,3\% de la pratique des médecins répondants est consacré à la dyspepsie, $23 \%$ des patients dyspeptiques consultent leur médecin à ce sujet pour la première fois, et $93 \%$ des médecins de famille trouvent utile le recours à une classification des symptômes de dyspepsie associés à un ulcère, à l'œesophagite de reflux et à la dysmotilité. La majorité des patients sont avisés de modifier leur style de vie et sont traités au moyen d'antiacides ou d'un traitement médicamenteux empirique. L'anti- $\mathrm{H}_{2}$ est le médicament de choix dans les cas de dyspepsie de type ulcère ou de type œsophagite de reflux, alors que les procinétiques sont souvent utilisés pour l'œsophagite de reflux et la dyspepsie de type dysmotilité. Après l'échec du traitement initial, les patients reçoivent un autre traitement empirique, souvent du cisapride ou de l'oméprazole. Les médecins de famille ont estimé que l'attente moyenne avant d'obtenir une consultation chez un gastro-entérologue était de cinq semaines et $70 \%$ ont indiqué que ce délai influait négativement sur leur décision d'adresser leurs patients. Si cette voir page suivante

${ }^{1}$ Surrey GI Clinic, Guelph, Ontario; ${ }^{2}$ Division of Gastroenterology, and ${ }^{4}$ Clinical Epidemiology and Biostatistics, McMaster University, Hamilton, Ontario; ${ }^{3}$ Innovus Research Inc, Burlington, Ontario

Correspondence and reprints: Dr Naoki Chiba, Surrey GI Clinic, 105-21 Surrey Street West, Guelph, Ontario N1H 3R3. Telephone 519-836-8201, fax 519-836-1341, e-mail chiban@fhs.mcmaster.ca

Received for publication June 9, 1997. Accepted October 28, 1997 
attente était ramenée à moins de deux semaines, les médecins ayant répondu au sondage adresseraient tous les patients admissibles. En moyenne, de 2 à 2,5 traitements empiriques ont été administrés avant que les patients ne soient adressés en gastro-entérologie. Les médecins qui connaissaient le statut du patient à l'égard de $H$. pylori prescrivaient moins de traitements empiriques (moyenne 1,8) avant d'adresser leurs patients en gastro-entérologie en comparaison avec les autres scénarios. Si le patient présentait une dyspepsie de type non ulcéreuse, $30 \%$ des médecins de famille se sont contentés de rassurer leur patient et n'ont pas prescrit de traitement médicamenteux empirique.

CONCLUSIONS : La plupart des patients souffrant de dyspepsie de fraîche date au Canada sont traités de façon empirique selon une classification des symptômes, puis adressés pour endoscopie après une moyenne de 2 à 2,5 traitements.
$\mathrm{D}$ yspepsia, defined as pain or discomfort centred in the upper abdomen, is a common condition. A Canadian study found that $38 \%$ of subjects complained of mild to moderate acid-related symptoms (1), which often leads to patient-driven empiric treatments with over-the-counter antacids and $\mathrm{H}_{2}$ receptor antagonists (2), physician visits, time off work and an adverse effect on the quality of life. Thus, the social and economic costs of dyspepsia are considerable (3). When confronted with a new onset dyspeptic patient, the physician cannot know whether an organic disease exists or whether the patient has a functional, nonlifethreatening but troublesome disorder. Because history alone lacks diagnostic discriminant value, the family physician must decide whether investigations are necessary or whether drug therapy without an initial diagnosis, so-called 'empiric therapy', is appropriate. In a patient with alarm symptoms, such as weight loss, dysphagia, bleeding or microcytic anemia, investigation clearly is required, but in their absence the choice is less clear.

The standard approach has been to follow the 1985 recommendations of the American College of Physicians and prescribe a course of empiric drug therapy, followed by endoscopy for those failing treatment (4). Do Canadian family physicians give the same empiric treatment to all patients or do they consider treatment according to the symptom subgroups of ulcer-like, reflux-like and dysmotility-like dyspepsia? The answer to this question is unknown.

The discovery of Helicobacter pylori has provided the opportunity to cure patients with duodenal and gastric ulcer disease. However, most patients with $H$ pylori are asymptomatic or are dyspeptic without organic disease and are classified as having nonulcer dyspepsia (NUD) or functional dyspepsia. It is important to distinguish undiagnosed dyspepsia from the diagnosis of NUD, made only after negative investigations. The association between $H$ pylori and NUD is controversial, although pooled analysis has shown that NUD patients have a $23 \%$ higher prevalence of $H$ pylori compared with controls (5). Also, inflammation associated with $H$ pylori infection might be expected to disturb antropyloroduodenal motility and other aspects that may contribute to dyspepsia (6). Reviews of $H$ pylori eradication therapy in NUD have not shown consistent benefit $(7,8)$. The role that diagnosis and treatment of $H$ pylori infection plays in the management of dyspepsia by Canadian family physicians is unknown.

The goal of this study was to determine the management of new onset dyspepsia by Canadian family physicians through the use of a structured questionnaire.

\section{MATERIALS AND METHODS}

A total of 195 family practitioners were selected randomly from across Canada and agreed to participate in an August 1995 survey on the management of new onset dyspepsia by mailing in a structured questionnaire.

The Rome criteria (9) defined three dyspepsia subgroups to aid the diagnosis of dyspepsia. Although the clinical utility of these criteria has been questioned (10), they do provide a conceptual framework that may assist physicians in patient management. In this section of the survey, the dyspepsia symptom classification of ulcer-like, reflux-like and dysmotility-like was explained. Physicians were asked whether they found this classification helpful. Other factors in the history that family physicians might consider helpful to manage dyspepsia were also asked.

Data on the initial and subsequent management of patients who returned with persistent dyspepsia were obtained from different scenarios. Within each scenario, family physicians were given the option of managing all patients the same way, regardless of specific symptoms, or differently, based on dyspepsia subgroups if they indicated that they would consider subgroups helpful in their management. Family physicians indicated which medication(s) they would prescribe.

The typical patient under consideration was a healthy 35-year-old presenting with new onset dyspepsia, without alarm symptoms and no prior investigations. Initially global management of new onset dyspepsia was determined, followed by whether management of a new dyspeptic patient would vary according to four hypothetical scenarios.

Scenario 1: Family physicians were asked what empiric therapy they would prescribe based on presenting symptoms only and without investigation.

Scenario 2: Family physicians were to assume that there was a readily available test for $\mathrm{H}$ pylori and to provide information based on a positive test for $H$ pylori to determine whether this influenced their management strategy.

Scenario 3: Family physicians were to assume that there was a readily available test for $H$ pylori and to provide information based on a negative test for $H$ pylori to determine whether this influenced their management strategy.

Scenario 4: Family physicians were to provide information for management strategies for patients who underwent initial endoscopy with normal findings (NUD), ie, based on the knowledge that there was no pathology to account for symptoms. 
Statistical methods: Descriptive statistics, cell frequencies and proportions were used to summarize data. Continuous variables are reported as mean $\pm \mathrm{SD}$.

\section{RESULTS}

Demographics and practice information: The physicians surveyed were from British Columbia $(n=14)$, Alberta $(n=10)$, Saskatchewan $(n=5)$, Manitoba $(n=6)$, Ontario $(n=82)$, Quebec $(n=55)$, Nova Scotia $(n=15)$ and Newfoundland $(n=8)$. A total of 179 of 195 questionnaires were returned. Nine questionnaires could not be used because answers were incomplete and could not be clarified by telephone because physicians were unavailable. Of the remaining 170 questionnaires, follow-up telephone calls clarified unclear responses, resulting in a high completion rate $(87.2 \%)$. The majority of respondents were male $(79.4 \%)$ and had been in practice for an average of nearly 20 years. Most were in nonacademic practice, confirming the generalizability of the survey findings. Most practised in an urban setting. Thus, the majority would have ready access to continuing medical education programs. Physicians were split evenly between group and solo practices.

The study group reported seeing a highly variable number of patients (mean 576 patients per month). An estimated 42 patients per month presented with dyspepsia, yielding a crude estimate of $7.3 \%$ of the practice being devoted to the management of dyspepsia. For just over half of the patients, dyspepsia was the primary reason for the physician visit, while for the others dyspepsia was additional to another complaint. Of patients suffering dyspepsia, family physicians estimated that a mean of $23 \%$ were presenting for the first time.

Clinical utility of dyspepsia subgroups: One hundred and thirty-three physicians (78.2\%) found a symptom subgroup classification (9) helpful when used in conjunction with other information (see below), and $14.7 \%$ considered the classification to be a primary factor in deciding treatment. Thus, $92.9 \%$ of physicians found a dyspepsia classification useful for patient management (the remainder found it of no value due to the overlap of symptoms).

Other factors in the history considered in the management of dyspepsia: Physicians were asked to indicate characteristics considered important in the management of dyspepsia. Acetylsalicylic acid (ASA) and nonsteroidal anti-inflammatory drug (NSAID) ingestion, presence of alarm symptoms and alcohol consumption were considered important by more than $95 \%$ of respondents. A total of $93.5 \%$ indicated that previous diagnosis and smoking were the next most important characteristics, followed by symptom severity (86.5\%), symptom duration $(85.9 \%)$, obesity $(75.9 \%)$ and age $(75.3 \%)$. Interestingly, only $33.5 \%$ considered sex an important factor. Other factors considered included stress, depression and anxiety (12\%), and whether symptoms were food-related (12\%).

Management strategies of new onset dyspepsia: Physicians were given four choices of how they would manage the new onset dyspeptic patient. Lifestyle changes and/or antacids only were suggested most frequently, with $52.2 \%$ of physicians using this approach. Empiric drug therapy based on the presenting symptom without initial investigations or diagnosis was recommended by $32.6 \%$. Only $12.9 \%$ indicated that they would test for $\mathrm{H}$ pylori before initiating treatment, and only $2.3 \%$ would refer the patient to a gastroenterologist for evaluation at initial presentation. Thus, approximately $85 \%$ of patients overall would be treated with either lifestyle changes or antacids (or other empiric therapy) at first presentation, and only a minority would undergo some form of investigation.

Recommended lifestyle changes: The most frequently recommended lifestyle changes were to stop smoking (95.6\%) and to avoid aggravating foods (95.3\%). Other advice included avoiding alcohol (89.4\%), avoiding going to bed soon after eating (85.9\%), eating smaller, well-balanced meals (84.1\%), achieving weight loss (80\%) and elevating the head of the bed $(65.9 \%)$. Some respondents recommended stress management and stress reduction (10\%) and the avoidance of ASA, NSAIDs or other potentially aggravating medications (11.1\%).

Physicians estimated that $44.2 \%$ of patients who were recommended to make lifestyle changes only would not be seen again within six months.

Patients given empiric therapy on initial presentation: Empiric therapy based on the presenting symptom was recommended by $32.6 \%$ of family physicians on initial presentation. If a patient was given empiric therapy, $52.4 \%$ of physicians left it up to the patient to return if symptoms recurred. Following an initial response, symptom recurrence was estimated to occur in about 10 weeks. If a patient responded initially, $49.6 \%$ of patients would require continued treatment for a mean of 6.4 months to maintain symptom relief. Patients given ongoing treatment would be seen approximately once per month.

Patients sent for gastroenterology referral at initial presentation: Only $2.3 \%$ of patients would be referred for consultation to a gastroenterologist at initial presentation. The average waiting time for consultation with a gastroenterologist was estimated to be 4.7 weeks, and $70 \%$ of respondents indicated that the waiting time influenced their management decision. If the waiting time was shortened to a mean of 1.8 weeks, respondents would refer all eligible patients for endoscopy. Of referred patients, $44.1 \%$ are sent specifically for endoscopy and the remainder for a consultation without specific expectations. A total of $45.4 \%$ of patients are referred back to the family physician for ongoing management.

Scenario 1 - Initial (first-line) empiric therapy based on presenting symptoms: Family physicians indicated that most patients $(82.9 \%)$ would be treated according to symptom subgroups, and only $16.5 \%$ of patients would be 'treated the same' regardless of the presenting complaint (Table 1). Physicians estimated that $36 \%$ of patients would present with ulcer-like, $37 \%$ with reflux-like and $27 \%$ with dysmotilitylike dyspepsia. After initial treatment, about $34 \%$ were estimated to relapse within six months.

From a total of 369 responses, drug treatments were 
TABLE 1

Scenario 1: Empiric therapy given based on presenting symptoms only

\begin{tabular}{|c|c|c|c|c|c|c|c|c|c|c|c|c|}
\hline \multirow[b]{2}{*}{ Drug class } & \multicolumn{3}{|c|}{ Treat all patients the same } & \multicolumn{3}{|c|}{ Ulcer-like } & \multicolumn{3}{|c|}{ Reflux-like } & \multicolumn{3}{|c|}{ Dysmotility-like } \\
\hline & $\begin{array}{l}\text { Initial } \\
(n=23)\end{array}$ & $\begin{array}{c}\text { 1st failure } \\
(n=33)\end{array}$ & $\begin{array}{c}\text { 2nd } \\
\text { failure } \\
(n=20)\end{array}$ & $\begin{array}{c}\text { Initial } \\
(n=155)\end{array}$ & $\begin{array}{c}\text { 1st } \\
\text { failure } \\
(n=165)\end{array}$ & $\begin{array}{c}\text { 2nd } \\
\text { failure } \\
(n=66)\end{array}$ & $\begin{array}{c}\text { Initial } \\
(n=135)\end{array}$ & $\begin{array}{c}\text { 1st } \\
\text { failure } \\
(n=189)\end{array}$ & $\begin{array}{c}\text { 2nd } \\
\text { failure } \\
(n=84)\end{array}$ & $\begin{array}{l}\text { Initial } \\
(n=56)\end{array}$ & $\begin{array}{c}\text { 1st } \\
\text { failure } \\
(n=150)\end{array}$ & $\begin{array}{c}\begin{array}{c}2 n d \\
\text { failure } \\
(n=74)\end{array} \\
\end{array}$ \\
\hline Antacids alone & $8.7(2)$ & $9.1(3)$ & 0 & $2.6(4)$ & $3.6(6)$ & $1.5(1)$ & $14.1(19)$ & $11.1(21)$ & $3.6(3)$ & $8.9(5)$ & $3.3(5)$ & $1.4(1)$ \\
\hline $\mathrm{H}_{2} \mathrm{RA}$ & $82.6(19)$ & $27.3(9)$ & $20.0(4)$ & $81.9(127)$ & $26.7(44)$ & $13.6(9)$ & $50.4(68)$ & $29.6(56)$ & $9.5(8)$ & $7.1(4)$ & $28.0(42)$ & $16.2(12)$ \\
\hline PPI & $8.7(2)$ & $45.5(15)$ & $30.0(6)$ & $13.5(21)$ & $52.1(86)$ & $53.0(35)$ & $15.6(21)$ & $26.5(50)$ & $52.4(44)$ & $1.8(1)$ & $5.3(8)$ & $24.3(18)$ \\
\hline $\begin{array}{l}\text { Prokinetic }+ \text { acid } \\
\text { suppression }\end{array}$ & 0 & 0 & 0 & 0 & 0 & 0 & $13.3(18)$ & 0 & 0 & $10.7(6)$ & $1.3(2)$ & 0 \\
\hline Antibiotics/Hp & 0 & $3.0(1)$ & $10.0(2)$ & $1.3(2)$ & $6.7(11)$ & $12.1(8)$ & 0 & $1.1(2)$ & $2.4(2)$ & 0 & 0 & $1.4(1)$ \\
\hline Miscellaneous & 0 & $3.0(1)$ & $5.0(1)$ & $0.6(1)$ & $55.5(9)$ & $7.6(5)$ & $3.0(4)$ & $1.6(3)$ & $7.1(6)$ & $23.2(13)$ & $14.0(21)$ & $23.0(17)$ \\
\hline
\end{tabular}

All results are expressed as $n$ (\%), except 'Proportion referred to $\mathrm{Gl}^{\prime}$ (gastroenterologist) which is expressed as mean \% \pm SD. $\mathrm{H}_{2} \mathrm{RA} \mathrm{H}_{2}$ receptor antagonist; $\mathrm{Hp}_{\mathrm{H}} \mathrm{Helico-}$ bacter pylori; PPI Proton pump inhibitor

pooled into general drug classes (Table 1). Antacids could be given alone or in combination with other drugs. The $\mathrm{H}_{2}$ receptor antagonist arm $\left(\mathrm{H}_{2} \mathrm{RA}\right)$ included cimetidine, ranitidine, famotidine and nizatidine. The patient was considered to have been given a proton pump inhibitor (PPI) (only omeprazole was available at the time of this survey) if the physician mentioned giving PPI alone or giving a PPI in combination with an antacid or a $\mathrm{H}_{2} \mathrm{RA}$, because the drug used was placed into the drug class with the greatest degree of acid suppression. If given with a prokinetic, it was placed into the prokinetic plus acid suppression (either omeprazole or a $\mathrm{H}_{2} \mathrm{RA}$ ) category. Prokinetics included cisapride, domperidone or metoclopramide. Miscellaneous drug therapies comprised sucralfate, any combination of three or more drugs, and a variety of anxiolytics and psychotropic drugs, antispasmodics and drugs for irritable bowel syndrome.

The most common empiric therapy was a $\mathrm{H}_{2} \mathrm{RA}$, used first-line in over $80 \%$ of patients in the treat all patients the same and the ulcer-like dyspepsia categories. Ranitidine was most commonly used, followed by nizatidine, then famotidine. Cimetidine, the least expensive $\mathrm{H}_{2} \mathrm{RA}$, was rarely mentioned. Omeprazole was the second most frequently given drug - but prescribed in fewer than $15 \%$ of cases among those given the same empiric therapy regardless of specific symptom(s) and those in the ulcer-like dyspepsia group. No prokinetic use was cited. Thus, almost all patients were given some form of acid suppressive treatment in these groups. In the ulcer-like dyspepsia category, only $1.3 \%$ of physicians prescribed empiric $H$ pylori eradication therapy. After initial treatment failure, most physicians would continue to give some form of empiric therapy and $64 \%$ to $71 \%$ would switch to a different class of medication. Thus, $\mathrm{H}_{2} \mathrm{RA}$ use was much reduced in this group of patients, and there was a switch to a PPI, offering more effective acid suppression.

For reflux-like symptoms, half the patients were given a
$\mathrm{H}_{2} \mathrm{RA}$, while antacids and omeprazole were each given in about $15 \%$ of cases. If prokinetics were given, they tended to be prescribed in combination with a $\mathrm{H}_{2} \mathrm{RA}$. After initial treatment failure, prokinetic use (mostly cisapride) increased and was used as commonly as the $\mathrm{H}_{2} \mathrm{RA}$ and omeprazole (about 30\% each). After a second failure, PPI was prescribed by half the respondents and $\mathrm{H}_{2} \mathrm{RA}$ use declined.

In dysmotility-like dyspepsia, prokinetic drugs were most commonly given, with domperidone usually prescribed, followed by metoclopramide. Cisapride was never given alone but occasionally in combination with one other drug. Antisecretory drugs, in particular omeprazole, were rarely prescribed in this symptom subgroup. One quarter of these patients received some form of miscellaneous combination of treatments, including trimebutine, antispasmodics and psyllium which are usually given for irritable bowel syndrome. Anxiolytics were also prescribed.

If initial empiric treatment failed, most patients would be investigated with an upper gastrointestinal barium study (about $71 \%$ ) or endoscopy (10\%), with a minority to be tested for $\mathrm{H}$ pylori (7.1\%). After initial treatment failure, only $29 \%$ patients are referred to a gastroenterologist, but after a second treatment failure, most patients (about $77 \%$ ) are referred. The mean number of empiric treatment courses given before referral was between 2.3 and 2.5.

Scenario 2 - Treatment based on a positive test for $\mathrm{H}$ pylori: If patients were known to be $H$ pylori-positive, the majority $(69.4 \%)$ would be treated the same independent of symptom subgroup, while the remainder would be treated based on the presenting symptom. This represents a shift in management compared with the first scenario, in which only $16.5 \%$ would be treated the same. Physicians considering treatment based on symptom subgroups thought the proportion of patients having ulcer-like dyspepsia with a positive test for $H$ pylori was $46.4 \%$, versus reflux-like $(32.8 \%)$ and dysmotility-like dyspepsia (26.1\%). 
TABLE 2

Scenario 3: Empiric therapy given if patient known to be Helicobacter pylori-negative

\begin{tabular}{|c|c|c|c|c|c|c|c|c|c|c|c|c|}
\hline \multirow[b]{2}{*}{ Drug class } & \multicolumn{3}{|c|}{ All patients the same } & \multicolumn{3}{|c|}{ Ulcer-like } & \multicolumn{3}{|c|}{ Reflux-like } & \multicolumn{3}{|c|}{ Dysmotility-like } \\
\hline & $\begin{array}{c}\text { Initial } \\
(\mathbf{n}=\mathbf{5 0})\end{array}$ & $\begin{array}{c}\text { 1st } \\
\text { failure } \\
(n=31)\end{array}$ & $\begin{array}{c}\text { 2nd } \\
\text { failure } \\
(n=22)\end{array}$ & $\begin{array}{c}\text { Initial } \\
(\mathbf{n}=\mathbf{1 5 0})\end{array}$ & $\begin{array}{c}1 \text { st } \\
\text { failure } \\
(n=115)\end{array}$ & $\begin{array}{c}2 n d \\
\text { failure } \\
(n=45)\end{array}$ & $\begin{array}{c}\text { Initial } \\
(n=139)\end{array}$ & $\begin{array}{c}\text { 1st } \\
\text { failure } \\
(n=149)\end{array}$ & $\begin{array}{c}\text { 2nd } \\
\text { failure } \\
(n=63)\end{array}$ & $\begin{array}{c}\text { Initial } \\
(n=138)\end{array}$ & $\begin{array}{c}\text { 1st } \\
\text { failure } \\
(n=130)\end{array}$ & $\begin{array}{c}\begin{array}{c}2 n d \\
\text { failure } \\
(n=60)\end{array} \\
\end{array}$ \\
\hline Antacids alone & $6.0(3)$ & $6.5(2)$ & 0 & $2.7(4)$ & $3.5(4)$ & 0 & $13.7(19)$ & $7.4(11)$ & $4.8(3)$ & $5.8(8)$ & $2.3(3)$ & $3.3(2)$ \\
\hline $\mathrm{H}_{2} \mathrm{RA}$ & $76.0(38)$ & $12.9(4)$ & $13.6(3)$ & $81.3(122)$ & $25.2(29)$ & $15.5(7)$ & $41.7(58)$ & $28.2(42)$ & $9.5(6)$ & $3.6(5)$ & $23.1(40)$ & $15.0(9)$ \\
\hline PPI & $6.0(3)$ & $58.1(18)$ & $50.0(11)$ & $14.7(22)$ & $61.7(71)$ & $57.8(26)$ & $12.2(17)$ & $29.5(44)$ & $52.4(33)$ & 0 & $3.1(4)$ & $16.7(10)$ \\
\hline $\begin{array}{l}\text { Prokinetic + acid } \\
\text { suppression }\end{array}$ & $6.0(3)$ & 0 & 0 & 0 & 0 & 0 & $19.4(27)$ & 0 & 0 & $8.7(12)$ & 0 & 0 \\
\hline Antibiotics/Hp & $2.0(1)$ & 0 & $9.1(2)$ & $0.7(1)$ & $0.9(1)$ & $2.2(1)$ & $0.7(10)$ & 0 & $1.6(1)$ & 0 & 0 & $1.7(1)$ \\
\hline Miscellaneous & $2.0(1)$ & $19.4(6)$ & $13.6(3)$ & $0.7(1)$ & $6.1(7)$ & $11.1(5)$ & $2.2(3)$ & $4.7(7)$ & $3.2(2)$ & $8.7(12)$ & $13.8(18)$ & $36.7(22)$ \\
\hline
\end{tabular}

All results are expressed as $n(\%)$, except 'Proportion referred to $\mathrm{Gl}^{\prime}$ (gastroenterologist) which is expressed as mean $\% \pm \mathrm{SD}$. $\mathrm{H}_{2} \mathrm{RA} \mathrm{H}_{2}$ receptor antagonist; Hp Helicobacter pylori; PPI Proton pump inhibitor

Of physicians who would likely treat all patients the same, $91.7 \%$ prescribed an antibiotic(s) in initial empiric therapy. When patients had ulcer-like dyspepsia, $74.1 \%$ would be given antibiotics. Antibiotics were given in only $44 \%$ of reflux-like and $30 \%$ of dysmotility-like dyspeptics. Of a total 270 treatments mentioned, 186 involved antibiotics, and there were 46 different regimens. The most popular regimen was dual therapy with omeprazole and amoxicillin (19.9\% of treatments) followed by triple therapy with omeprazole, amoxicillin and metronidazole (17.7\%). Bismuth triple therapies were used in $10.8 \%$ of cases, omeprazole, clarithromycin and metronidazole in 6.5\% (12 of 186), and omeprazole, clarithromycin and amoxicillin in only $4.8 \%$ (nine of 186). Thus, the most effective treatments for $\mathrm{H} p \mathrm{p}$ lori eradication were the least commonly given.

Multiple drug combinations were prescribed primarily in the dysmotility-like group and to a lesser extent in the reflux-like group. In the dysmotility-like group, prokinetics were mentioned in 35 of 46 responses $(76.1 \%)$. Cisapride was used alone in $49 \%$, and in combination with antibiotics in $26 \%$, with one response each with an anxiolytic, $\mathrm{H}_{2} \mathrm{RA}$ and omeprazole. It is noteworthy that several physicians used cisapride in combination with clarithromycin, a potentially lethal combination (see 'Discussion'). Domperidone and metoclopramide were infrequently used.

There was a trend towards fewer courses of empiric therapy given in the treat all patients the same and ulcer-like dyspepsia groups (1.8 each) compared with the reflux-like (2.0) or dysmotility-like groups (2.1) before referral to a gastroenterologist. After initial treatment failure, more treat all patients the same $(71 \%)$ and ulcer-like dyspepsia (75\%) patients were referred to a gastroenterologist than in reflux-like $(62 \%)$ or dysmotility-like (55\%) dyspepsia subgroups. After failure of a second empiric therapy, most patients (78\% to 91\%) were referred.
Scenario 3 - Treatment based on a negative test for $\mathrm{H}$ pylori: Family physicians indicated that $22.9 \%$ of patients would be treated the same regardless of symptoms and the remainder would be treated according to dyspepsia subgroups (Table 2). This figure is similar to the $16.5 \%$ when empiric treatment was used when $H$ pylori status was unknown (scenario 1 ), but much less than the $69.4 \%$ when a patient was known to be $H$ pylori-positive. The distribution of empiric treatments in the treat all patients the same and ulcer-like dyspepsia groups was similar to scenario 1 , and $\mathrm{H}_{2} \mathrm{RA}$ use predominated. After initial and second treatment failure, there was a change in prescribing patterns compared with that in scenario 1. In the treat all patients the same group, there was less $\mathrm{H}_{2} \mathrm{RA}$ and prokinetic use, omeprazole use was unchanged, and there was an increase in miscellaneous treatments. These included sucralfate, misoprostol and psychotropic drugs. In the ulcer-like dyspepsia group, $\mathrm{H}_{2} \mathrm{RA}$ treatment decreased while omeprazole use increased.

In the reflux-like dyspepsia group, there was slightly less $\mathrm{H}_{2} \mathrm{RA}$ and omeprazole use compared with initial therapy in scenario 1 (Tables 1,2). Prokinetics were used more frequently alone and in combination with an antisecretory agent, usually a $\mathrm{H}_{2} \mathrm{RA}$. After initial and second treatment failure, prescribing patterns remained consistent with the same distribution of $\mathrm{H}_{2} \mathrm{RA}$, omeprazole and prokinetics as in scenario 1. Interestingly, some regimens included prescriptions of three or four drugs of different classes.

In the dysmotility-like dyspepsia group, overall there were fewer antacids, $\mathrm{H}_{2} \mathrm{RA}$ and miscellaneous combinations used than in scenario 1 . There was a substantial increase in prokinetic use, predominantly cisapride, with occasional domperidone but rarely metoclopramide. In this symptom subgroup, there was no increase in combination treatment with prokinetics and acid suppression, as seen in the refluxlike group. 
TABLE 3

Scenario 4: Empiric therapy given if patient's endoscopy known to be negative (nonulcer dyspepsia)

\begin{tabular}{|c|c|c|c|c|c|c|c|c|c|c|c|c|}
\hline \multirow[b]{2}{*}{ Drug class } & \multicolumn{3}{|c|}{ All patients the same } & \multicolumn{3}{|c|}{ Ulcer-like } & \multicolumn{3}{|c|}{ Reflux-like } & \multicolumn{3}{|c|}{ Dysmotility-like } \\
\hline & $\begin{array}{l}\text { Initial } \\
(n=52)\end{array}$ & $\begin{array}{c}\text { 1st } \\
\text { failure } \\
(n=41)\end{array}$ & $\begin{array}{l}\text { 2nd failure } \\
(\mathrm{n}=20)\end{array}$ & $\begin{array}{l}\text { Initial } \\
(n=73)\end{array}$ & $\begin{array}{c}\text { 1st } \\
\text { failure } \\
(n=61)\end{array}$ & $\begin{array}{c}\begin{array}{c}2 n d \\
\text { failure } \\
(n=24)\end{array} \\
\end{array}$ & $\begin{array}{l}\text { Initial } \\
(n=67)\end{array}$ & $\begin{array}{c}\text { 1st } \\
\text { failure } \\
(n=69)\end{array}$ & $\begin{array}{c}\text { 2nd } \\
\text { failure } \\
(n=33)\end{array}$ & $\begin{array}{c}\text { Initial } \\
(n=70)\end{array}$ & $\begin{array}{c}1 s t \\
\text { failure } \\
(n=55)\end{array}$ & $\begin{array}{c}\begin{array}{c}2 n d \\
\text { failure } \\
(n=29)\end{array} \\
\end{array}$ \\
\hline Antacids alone & $15.4(8)$ & $9.8(4)$ & 0 & $5.5(4)$ & $4.9(3)$ & $9.0(6)$ & $5.8(4)$ & $6.1(4)$ & $6.1(2)$ & 0 & $3.6(2)$ & $3.4(1)$ \\
\hline $\mathrm{H}_{2} \mathrm{RA}$ & $38.5(20)$ & $26.8(11)$ & $20.0(4)$ & $75.3(55)$ & $23.0(14)$ & $12.5(3)$ & $32.8(22)$ & $26.1(18)$ & $15.2(5)$ & $2.9(2)$ & $21.8(12)$ & $10.3(3)$ \\
\hline PPI & $5.8(3)$ & $36.6(15)$ & $35.0(7)$ & $12.3(9)$ & $45.9(28)$ & $54.2(13)$ & $19.4(13)$ & $29.0(20)$ & $36.4(12)$ & 0 & $7.3(4)$ & $20.7(6)$ \\
\hline $\begin{array}{l}\text { Prokinetic }+ \text { acid } \\
\text { suppression }\end{array}$ & $3.8(2)$ & 0 & 0 & 0 & 0 & 0 & $19.4(13)$ & 0 & 0 & $2.9(2)$ & $1.3(2)$ & 0 \\
\hline Antibiotics/Hp & $1.9(1)$ & 0 & 0 & $2.7(2)$ & $3.2(2)$ & 0 & 0 & $2.9(2)$ & 0 & 0 & 0 & $10.3(3)$ \\
\hline Miscellaneous & $11.5(6)$ & $12.2(5)$ & $25.0(5)$ & $4.1(3)$ & $11.5(7)$ & $8.3(2)$ & $1.5(1)$ & $2.9(2)$ & 0 & $17.1(12)$ & $18.1(10)$ & 20.7 (6) \\
\hline
\end{tabular}

All results are expressed as $n$ (\%), except 'Proportion referred to $\mathrm{Gl}^{\prime}$ (gastroenterologist) which is expressed as mean \% \pm SD. $\mathrm{H}_{2} \mathrm{RA} \mathrm{H}_{2}$ receptor antagonist; $\mathrm{Hp}_{\mathrm{H}} \mathrm{Helico-}$ bacter pylori; PPI Proton pump inhibitor

After failure of a first empiric treatment, family physicians estimated that about $40 \%$, and after a second treatment failure about $79 \%$, of patients would be referred to a gastroenterologist. On average 2.2 to 2.4 empiric courses of therapy would be given before referral.

Scenario 4 - Treatment of patient with confirmed NUD: Knowledge that the patient had a normal endoscopy influenced patient management in the majority of cases $(65.3 \%)$ (Table 3 ). Thirty per cent of physicians indicated that they would reassure their patient only and not start any medication, while $34.7 \%$ felt that they would treat patients differently based on negative endoscopic findings.

In this scenario, initial empiric therapy was the same in $43 \%$ of respondents, while the remainder gave treatments based on the dyspepsia subgroups. Family physicians estimated that the proportion of patients from each dyspepsia subgroup would be approximately one-third each.

Initial empiric therapy in the treat all patients the same group was different compared with the empiric therapy in scenario 1 (Table 1). There was more antacid and prokinetic use, $\mathrm{H}_{2} \mathrm{RA}$ use was much less common and omeprazole was rarely used. In ulcer-like dyspepsia, the treatments were similar. In reflux-like dyspepsia, antacid and $\mathrm{H}_{2} \mathrm{RA}$ use were less common and prokinetic use increased, either alone or in combination with acid suppression. In dysmotility-like dyspepsia, there was much less antacid use, less $\mathrm{H}_{2} \mathrm{RA}$ use, and more prokinetic use alone but less in combination with acid suppression. Omeprazole was not used. In all groups, psychotropic drugs were used more frequently than in scenario 1 , although overall use was still minimal.

After a first treatment failure, more psychotropic drugs were prescribed. In general, the treatment trends in each subgroup were similar to those in scenario 1 . In ulcer-like dyspepsia, prokinetic use was increased slightly and antibiotic use was slightly less.

After the failure of a second empiric treatment (Table 3), more prokinetic use, but no antibiotic use, was reported to treat ulcer-like dyspepsia. In reflux-like dyspepsia, there was less omeprazole and more prokinetic use. In the dysmotilitylike group, antibiotics were prescribed for three patients; in previous scenarios antibiotics were not used.

After initial treatment failure, $29.6 \%$ to $44.5 \%$ of patients would be referred to a gastroenterologist. After a second treatment failure, $53 \%$ to $66 \%$ of patients would be referred, a figure lower than in other strategies. More courses of empiric therapy would be given (2.2 to 2.5) before referral, compared with the $\mathrm{H}$ pylori-positive scenario, but the referral rates are almost identical to those in scenario 1 in which no prior investigations were performed.

\section{DISCUSSION}

We report the results of a questionnaire mailed to Canadian family physicians to determine their current management approaches to patients with new onset dyspepsia. Dyspepsia is a common presenting complaint to family physicians, who estimated an average of $7.3 \%$ of their practice is devoted to dyspeptic patients.

Although there is controversy about the utility of defining dyspepsia subgroups, $92.9 \%$ of respondents felt that they were useful for patient management. Most felt the classification was useful when used in conjunction with other information, such as the presence of alarm symptoms, a history of ASA and/or NSAID ingestion, alcohol consumption, previous diagnosis and smoking habits. While physicians considered ASA or NSAID ingestion to be important, only $11 \%$ suggested avoiding these medications. Psychological factors such as stress, depression and anxiety were felt to play a minimal role as reflected by the few treatments aimed at these factors.

Nearly all respondents indicated that some proportion of their patients would receive lifestyle counselling and advice on conservative measures including as required antacid use. 
A minority of respondents would test for $\mathrm{H}$ pylori before initiating treatment or would refer the patient to a gastroenterologist for further evaluation.

At initial presentation family physicians rarely referred patients to a gastroenterologist; $70 \%$ indicated that the waiting time for consultation was too long, and this influenced their decisions. If the waiting time could be shortened to about two weeks, all eligible patients would be referred for endoscopy. This is an important finding in light of the results from a Danish study (11), in which patients who were specifically managed on the results from initial endoscopy had much greater satisfaction with their medical care, fewer days off work and, overall, reduced costs of treatment compared with those managed by initial empiric $\mathrm{H}_{2} \mathrm{RA}$ treatment. A new study by the same group (12) randomized dyspeptic patients in primary care to $\mathrm{H}$ pylori testing or immediate endoscopy. $H$ pylori-positive patients received eradication therapy and $H$ pylori-negative patients received a PPI if they had reflux symptoms and were endoscoped if they took NSAIDs. Interim results of this study have shown better symptom improvement and more satisfaction with the initial endoscopy strategy compared with the $H$ pylori test and eradicate strategy.

The present questionnaire identified that a normal endoscopy result (scenario 4) influenced physician management, because $30 \%$ of respondents indicated that they would provide only reassurance without prescribing any drug therapy. This finding supports initial endoscopy, which may provide the most effective and potentially cost-effective strategy for managing dyspepsia. However, the current lack of readily available immediate endoscopy limits this approach in Canada.

We presented four clinical scenarios to determine primary care management strategies. The first was intended to mimic usual family practice in which an otherwise well patient presented with new onset dyspepsia (scenario 1). This was considered a 'standard practice' to which the other scenarios could be compared. The majority of patients were treated according to their predominant symptom, while a minority were treated with the same empiric therapy regardless of the presenting symptom. On average, two to 2.5 courses of empiric therapy were given regardless of the presenting complaint before the patient was referred to a gastroenterologist. Because patients are not referred early, it is important that prescribing patterns reflect a logical switch in drug classes.

The $H$ pylori-positive group was managed substantially differently from the others. In contrast to treatment in the other scenarios, more patients were treated the same, and knowledge that the patient was $H$ pylori-positive influenced management decisions. Antibiotics were commonly prescribed, predominantly in the treat all patients the same and ulcer-like groups, with less antibiotic use in the reflux-like and dysmotility-like subgroups. Many respondents used dual therapies that are now outdated, but this probably is a reflection of practice at the time when this questionnaire was completed. The most effective PPI-based triple therapies containing clarithromycin were used only occasionally. Forty-six different eradication regimens were reported, and many involved a single antibiotic or ineffective combinations. In some instances, physicians reported using cisapride in combination with clarithromycin. This potentially dangerous combination may cause prolongation of the QT interval, and physicians are specifically cautioned about this interaction.

In the $H$ pylori-positive group there was a trend towards fewer courses of empiric therapy given in the treat all patients the same and ulcer-like dyspepsia groups (1.8 each) before referral. We speculate that family physicians associated a positive $H$ pylori test with more organic pathology and thus obtained an earlier gastroenterology consultation.

Several studies suggest that testing for $\mathrm{H}$ pylori and treating those who are positive, while reserving endoscopy for treatment failures, is the most cost-effective strategy. A recent American cost-effectiveness model (13) suggested that treating known $H$ pylori-positive patients with initial $H$ pylori eradication therapy is more cost-effective than initial endoscopy in managing dyspepsia. A clinical trial of this strategy is required to provide prospective data without the assumptions used in models to determine the most effective and most cost-effective treatments.

Empiric therapy in the other three scenarios was similar. In the treat all patients the same and ulcer-like dyspepsia groups, initial empiric therapy usually consisted of a $\mathrm{H}_{2} \mathrm{RA}$. A PPI was rarely used as initial treatment, and prokinetic use was minimal except in the NUD scenario in which it was the second most commonly prescribed drug (Table 3 ). After initial treatment failure, more potent acid suppression was usually prescribed, and thus omeprazole use increased as $\mathrm{H}_{2} \mathrm{RA}$ use decreased. Because ulcer disease is considered an acidrelated disorder, this change in medication is rational and appropriate. However, an alternative strategy in dyspeptic patients younger than 50 years old with ulcer-like symptoms is to test for $\mathrm{H}$ pylori and eradicate if $\mathrm{H}$ pylori-positive.

In patients with reflux-like dyspepsia, initial treatment was usually with a $\mathrm{H}_{2} \mathrm{RA}$, most commonly ranitidine, while cimetidine was rarely used. With initial failure of treatment there was increased prescribing of PPIs or a prokinetic, given in equal proportions. It was only after the second failure that omeprazole use became predominant. There was relatively little prescribing of a prokinetic along with an acid suppressive agent.

In dysmotility-like dyspepsia, initial therapy was usually a prokinetic agent, with acid suppression prescribed in the minority of cases. There were also more treatments with antispasmodics, trimebutine or treatments more commonly given for irritable bowel syndrome. Psychotropic drugs, including anxiolytics and antidepressants, were occasionally used. After a treatment failure, there was more prescribing of $\mathrm{H}_{2} \mathrm{RA}$ and PPI, which reflects an attempt to provide effective symptom relief with a change in drug class. There was also more use of combination treatments, perhaps reflecting the lack of understanding of symptom causation. Some re- 
spondents combined as many as four different drugs, which is not appropriate.

$H$ pylori eradication therapy was rarely given empirically without knowledge of $\mathrm{H}$ pylori status, even for patients in the ulcer-like dyspepsia subgroup. This finding is consistent with current understanding and recommendations.

\section{CONCLUSIONS}

The prescribing of empiric therapy for patients with dyspepsia was generally rational and logical. However, given the theoretical setting of a questionnaire, it is not possible to determine whether prescribing practices were appropriate.

ACKNOWLEDGEMENTS: This study was presented at the inaugural 1996 Canadian Digestive Disease Week meeting held in Banff, Alberta. The authors thank Astra Canada for arms-length financial support to Innovus Research Inc for data collection and management, and the family physicians who completed the survey.

\section{REFERENCES}

1. Tasch RF, Fenton A. Incidence of common gastrointestinal complaints and patient treatment patterns in Canada. Pharmacoepidemiol Drug Safety 1995;4:S51.

2. Hunt RH. Habit, prejudice, power and politics: issues in the conversion of $\mathrm{H}_{2}$-receptor antagonists to over-the-counter use. Can Med Assoc J 1996;154:49-53.
3. Colin-Jones DG, Bloom B, Bodemar G, et al. Management of dyspepsia: Report of a working party. Lancet 1988;i:576-9.

4. Kahn KL, Greenfield S, Health and Public Policy Committee ACOP. Endoscopy in the evaluation of dyspepsia. Position paper. Ann Intern Med 1985;102:266-9.

5. Armstrong D. Helicobacter pylori infection and dyspepsia. Scand J Gastroenterol 1996;31:38-47.

6. Armstrong D, Hunt RH. Helicobacter pylori and dyspepsia: a conceptual approach. In: Hunt RH, Tytgat GNJ, eds. Helicobacter pylori: Basic Mechanisms to Clinical Cure. Lancaster: Kluwer Academic Publishers, 1996:324-39.

7. Talley NJ. A critique of therapeutic trials in Helicobacter pyloripositive functional dyspepsia. Gastroenterology 1994;106:1174-83.

8. Veldhuyzen van Zanten SJO, Cleary C, Talley NJ, et al. Drug treatment of functional dyspepsia: a systematic analysis of trial methodology with recommendations for design of future trials. Am J Gastroenterol 1996;91:660-73.

9. Talley NJ, Colin-Jones D, Koch KL, Koch M, Nyren O, Stanghellini V. Functional dyspepsia: a classification with guidelines for diagnosis and management. Gastroenterology Int 1991;4:145-60.

10. Talley NJ, Zinsmeister AR, Schleck CD, Melton LJ. Dyspepsia and dyspepsia subgroups: A population based study. Gastroenterology 1992;102:1259-68.

11. Bytzer P, Hansen JM, Schaffalitzky de Muckadell OB. Empirical $\mathrm{H}_{2}$-blocker therapy or prompt endoscopy in management of dyspepsia. Lancet 1994;343:811-6.

12. Lassen AT, Bytzer P, Schaffalitzky de Muckadell OB. H pylori testing or prompt endoscopy for dyspeptic patients in primary care. A randomized controlled trial of two management strategies. Gastroenterology 1997;112:A24.

13. Ofman JJ, Etchason J, Fullarton S, Kahn KL, Soll AH. Management strategies for Helicobacter pylori-seropositive patients with dyspepsia: Clinical and economic consequences. Ann Intern Med 1997;126:280-91. 


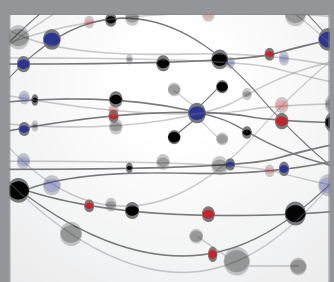

The Scientific World Journal
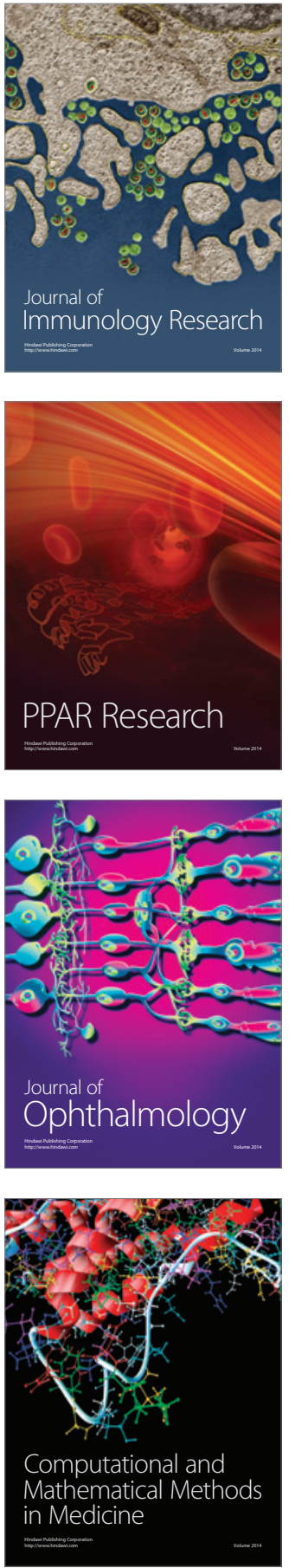

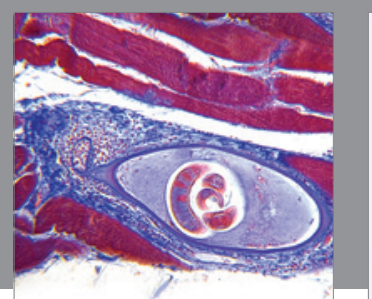

Gastroenterology Research and Practice

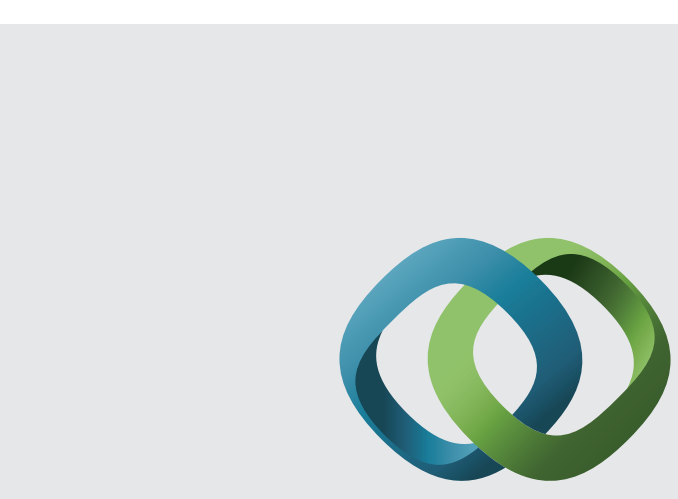

\section{Hindawi}

Submit your manuscripts at

http://www.hindawi.com
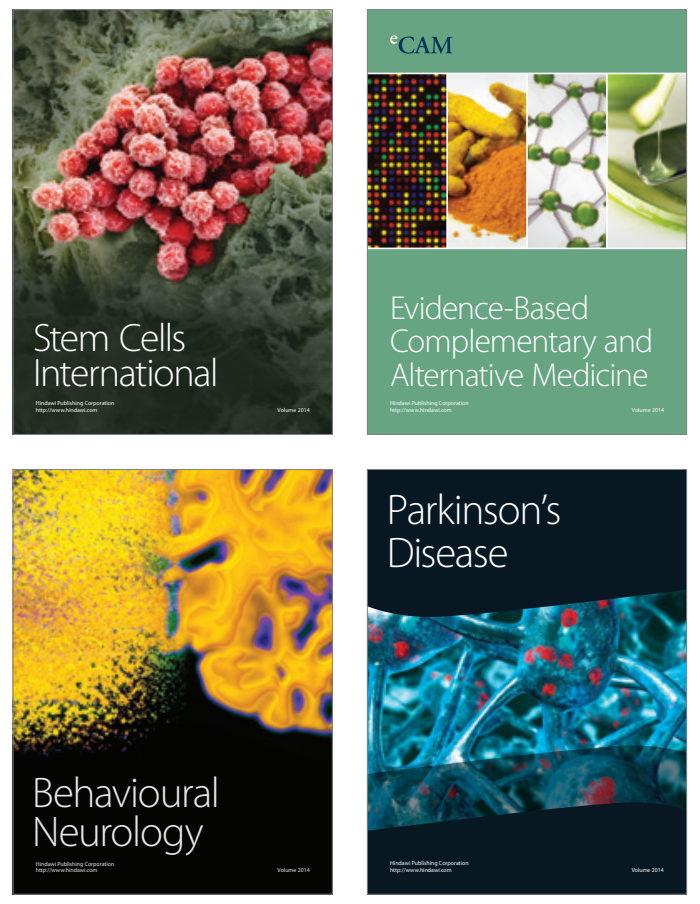
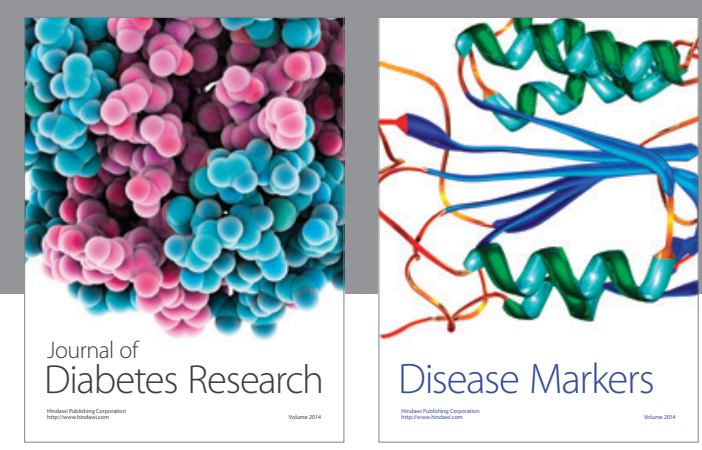

Disease Markers
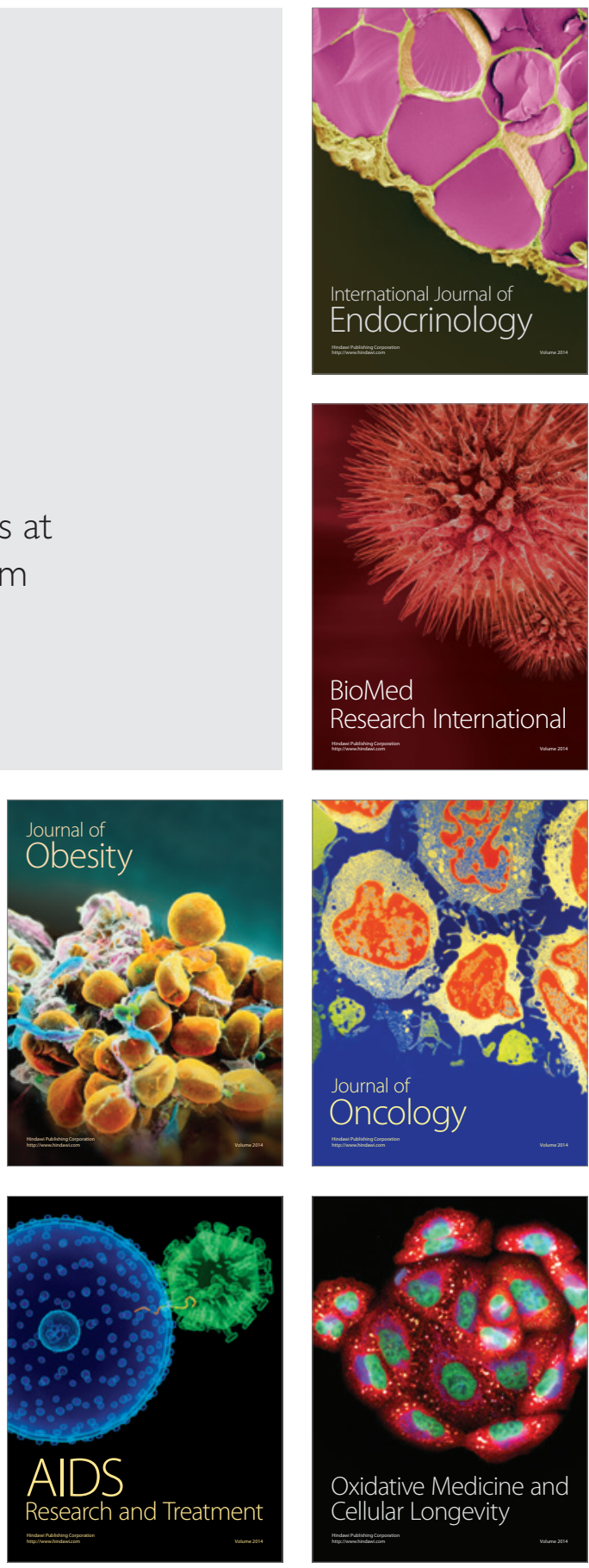